\title{
Growing Teratoma Syndrome: Two case reports
}

anju shrestha ${ }^{1}$, Hari Dhakal ${ }^{2}$, Sirish Pandey $^{3}$, Kapendra Amatya ${ }^{3}$, Sudip Shrestha ${ }^{3}$, Prakash Tiwari ${ }^{3}$, and Srijana Lama ${ }^{3}$

${ }^{1}$ Nepal cancer Hospital and Research center

${ }^{2}$ Nepal Cancer Hospital and Research center.

${ }^{3}$ Nepal Cancer Hospital and Research Center

December 8, 2021

\begin{abstract}
We present two cases of nine and twenty-seven years old girls with recurrence of immature teratoma after an incomplete surgical staging. In both cases, there were huge abdominopelvic masses despite decrease in tumor markers with chemotherapy. Complete surgical resection of these masses was done, and histopathology showed only mature teratoma.
\end{abstract}

\section{Hosted file}

manuscript case report.docx available at https://authorea.com/users/440929/articles/548587growing-teratoma-syndrome-two-case-reports

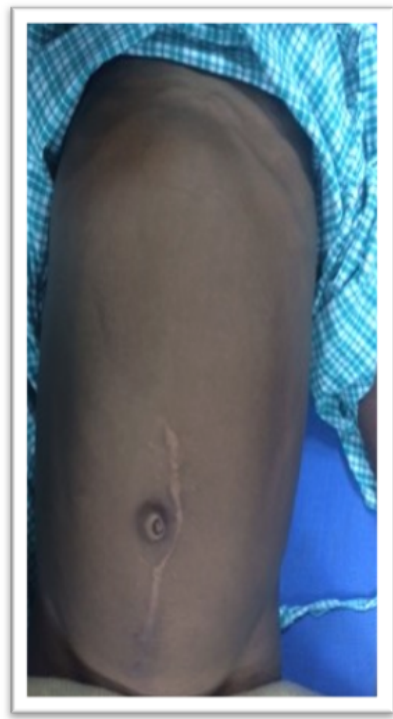

Figure $1 \mathrm{~A}$

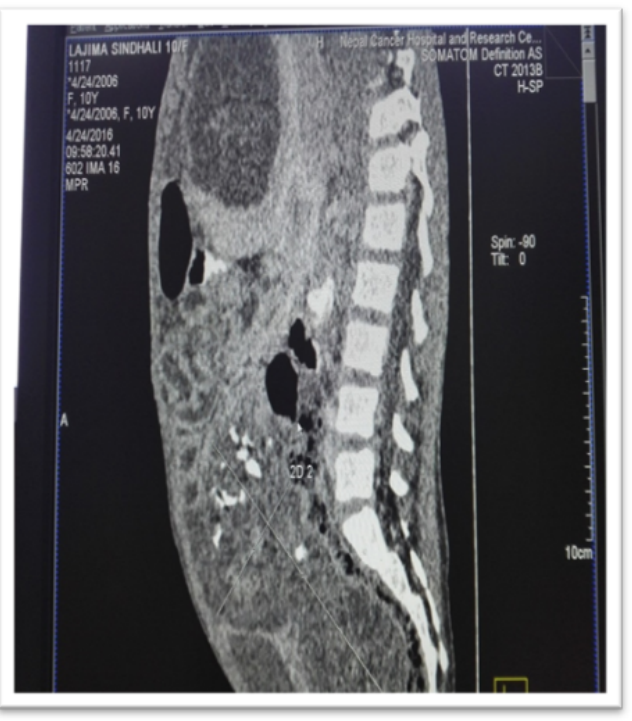

Figure 1 B 


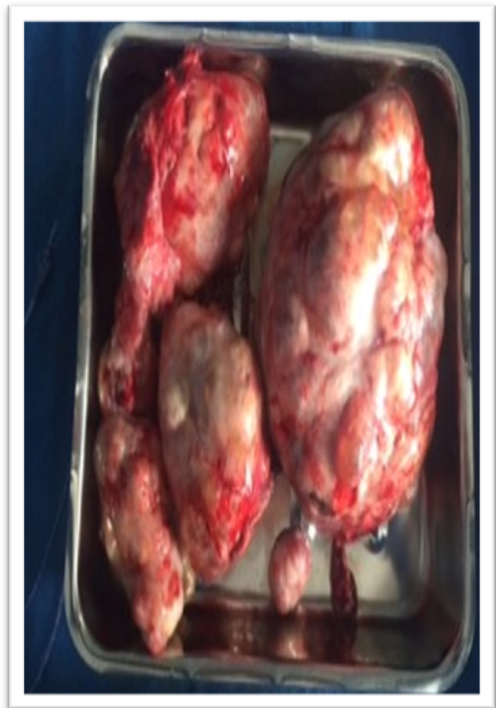

Figure $2 \mathrm{~A}$

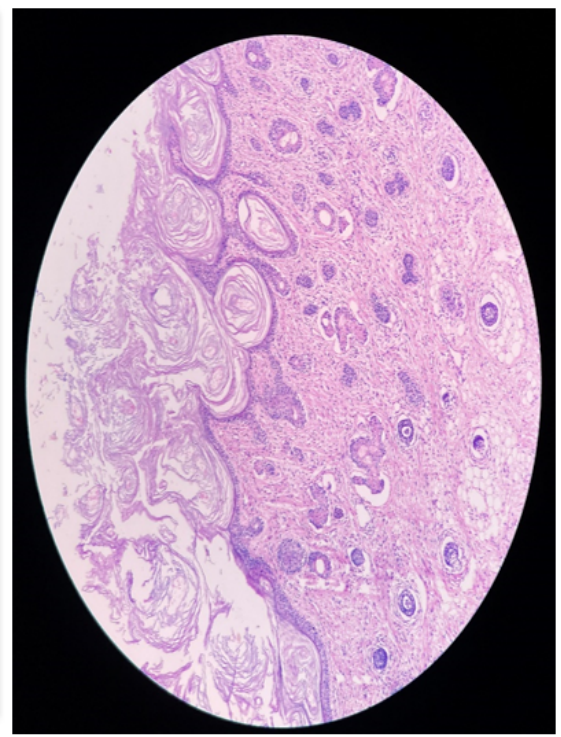

Figure 2 B

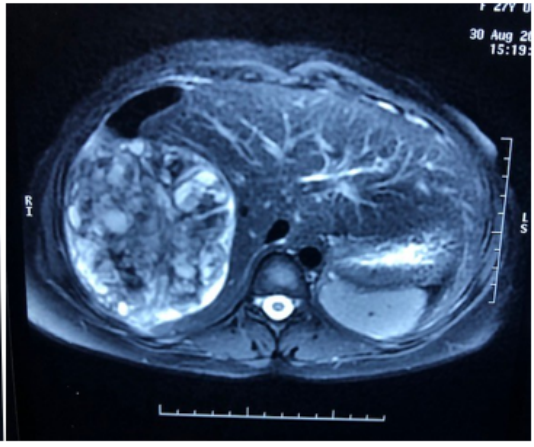

Figure 3 B

Figure 3 A

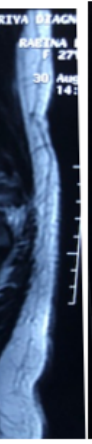




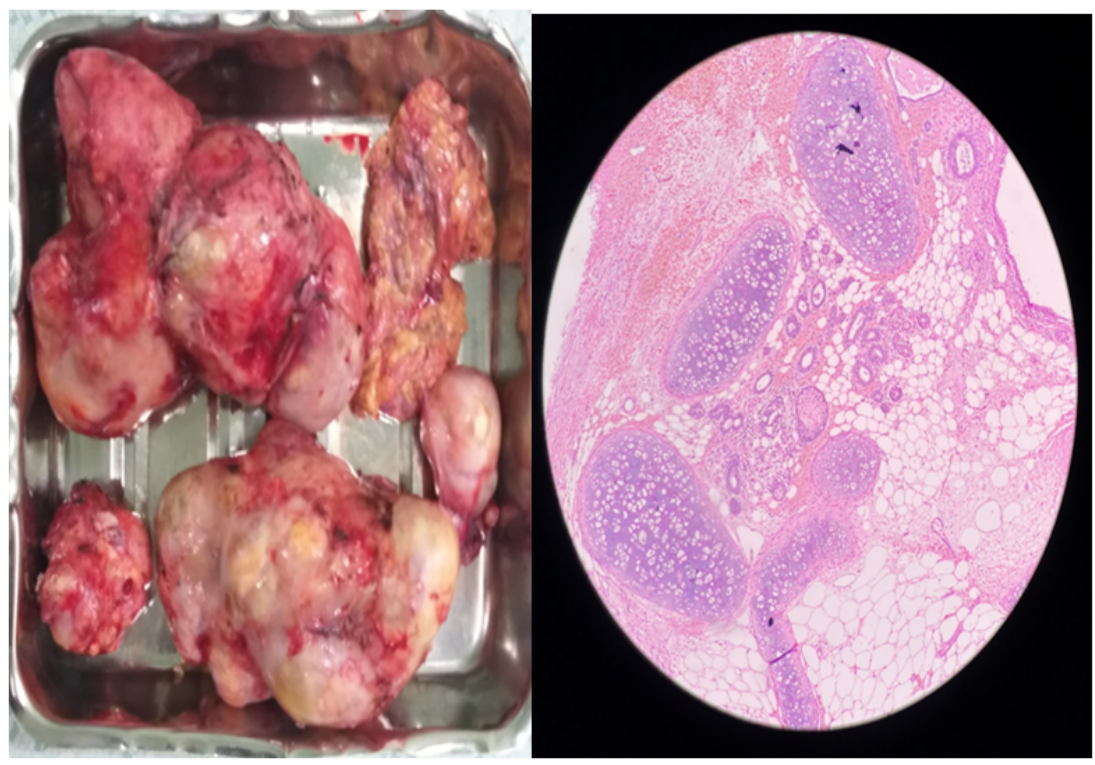

Figure $4 \mathrm{~A}$

Figure 4 B 